\title{
Docência, governo e verdade: elementos para uma análise anarqueológica
}

\author{
Roberto Rafael Dias da Silva*
}

\section{Resumo}

O presente artigo examina dois jogos de verdades que são mobilizados na constituição da docência contemporânea, a saber: a reflexividade pedagógica e o compromisso político do professor. Tal entendimento alicerça-se na perspectiva de que as verdades não são produzidas a priori das práticas escolares, nem mesmo constituem-se em um núcleo essencial do discurso pedagógico. Essas verdades conduzem a fabricação de sistemas de raciocínio pedagógico na medida em que interagem com as pautas sociais de seu tempo. Entretanto, esses sistemas contam permanentemente com a adesão dos professores, uma vez que, segundo as indicações que o filósofo Michel Foucault apresentou no curso de 1980, as verdades constituem-nos na medida em que inclinamo-nos ao seu poder, assumindo-a como forma de viver no verdadeiro.

Palavras-chave: Docência. Governo. Michel Foucault. Filosofia da educação.

Essa transformação de alguém que não sabe em alguém que sabe é o problema dos socráticos, é o problema de Platão, é todo o problema da educação, da retórica, da arte de persuadir, é finalmente o problema da democracia: para governar a cidade é necessário transformar esses que não sabem naqueles que sabem? É preciso transformar todos que não sabem em pessoas que sabem? (FOUCAULT, 2010, p. 54) 


\section{Introdução}

As condições contemporâneas de uma sociedade de aprendizagem apresentam-nos novos desafios para as investigações acerca dos processos de formação humana. Enquanto o século XVIII impulsionou-nos aos limites de um modelo de educação alicerçado nas instituições escolares, tão bem descrito nos diferentes regimes disciplinares, a contemporaneidade posiciona-nos na direção de inúmeros deslocamentos. Para além de superar as metanarrativas de uma educação multidimensional, nosso tempo assiste a uma multiplicação dos espaços educativos. Os divulgadores da nova pedagogia, arautos de um mundo globalizado e em conexões permanentes, provocam-nos a pensar desde as condições de uma educação que se dá em todos os espaços: nas cidades, nas mídias, nas políticas ambientais, no consumo, nas escolas e nas diferentes arenas democráticas contemporâneas.

Ao mesmo tempo em que a educação está em todos os lugares, sob a gramática das políticas do neoliberalismo, os sujeitos são interpelados a produzirem-se de outros modos. Na medida em que as teias do Estado keynesiano são desfeitas, diferentes regimes de individualização das responsabilidades coletivas são colocados em cena para a produção de novas subjetividades - mais interativas e flexíveis, por um lado, e mais inclusivas e democráticas, por outro lado. O ponto central da tradição pedagógica atualiza-se, tal como delineamos na epígrafe para este texto. Como devem ser formados os sujeitos da educação contemporânea? Que sentidos políticos e de organização da vida social regulam as novas subjetividades? Quais políticas regulam e gerenciam tais processos?

Conduzir os sujeitos a lugares diferenciados apresentou-se como a tarefa histórica dos processos pedagógicos. As promessas da emancipação, da conscientização, da maioridade e, sobretudo, da autonomia caracterizaram a produção e a constituição da ação dos professores, orientaram a produção de seus saberes e normatizaram seus modos de agir profissionais. A docência, compreendida enquanto um conjunto de práticas de condução, demarca preliminarmente duas condições, a saber, por um lado, regula as políticas e práticas de escolarização; por outro lado, inventa os sujeitos envolvidos nessa trama: o professor e o estudante. Nessa lógica, constituir-se professor implica em aceitar e promover os marcos regulatórios da tarefa pública da educação e, ao mesmo tempo, implica em exercer sobre si mesmo as promessas de uma vida submetida à verdade.

O curso de Michel Foucault no Collège de France proferido em 1980, Do governo dos vivos, marca alguns deslocamentos importantes na produção acadêmica do filósofo francês. Modificando a direção dos cursos ministrados nos três anos anteriores, Foucault apresenta uma nova direção para seus estudos naquele ano - o 
governo pela verdade. Fica evidenciado um deslocamento das discussões do saber-poder, que marcaram fortemente seu período de investigação genealógica, para a problematização do governo. $\mathrm{O}$ entendimento de governo visibilizado naquele momento pode ser tomado no sentido de "mecanismos e procedimentos destinados a conduzir os homens, a dirigir a conduta dos homens" (FOUCAULT, 2010, p. 43).

Diferentemente de pensar o governo desde o nascimento da razão de Estado, como o fez no curso de 1978, ou ainda de situá-la na grade do neoliberalismo, tal como em Nascimento da Biopolítica, no curso de 1980, Foucault procura ligar a arte de governar ao jogo da verdade.

Gostaria de tentar mostrar como não é possível dirigir os homens sem fazer operações da ordem da verdade, mas com o cuidado que essas operações da ordem da verdade sejam sempre excedentes em relação a isso que é útil e necessário para governar de uma maneira eficaz. É para além da finalidade eficaz, da finalidade em governar de modo eficaz, é sempre para além disso que a manifestação da verdade é requerida ou implicada ou ligada a uma atividade de governar e de exercer o poder (FOUCAULT, 2010, p. 49).

Para tratar das relações entre a manifestação da verdade e o exercício do poder, o filósofo francês retomou uma expressão grega utilizada pelo gramático Heráclide - "o adjetivo alêthourguês para designar alguém que diz a verdade" (2010, p. 35). A partir do adjetivo grego, Foucault forja a palavra aleturgia para referir-se ao conjunto de procedimentos pelos quais a verdade atualiza-se. "Poder-se-ia chamar aleturgia esse conjunto de procedimentos e dizer que não existe exercício de poder sem qualquer coisa como uma aleturgia" (2010, p. 36). Acerca desses procedimentos aletúrgicos é que refletiremos as políticas e as práticas de constituição da docência na contemporaneidade. Procuraremos desencadear algumas análises transversais, de materiais heterogêneos, posicionando a docência nas tramas do governo de si e dos outros.

\section{Uma análise anarqueológica: as aleturgias e seus procedimentos}

Tomando como ponto de partida os personagens de Édipo, Foucault propõe-se a analisar duas formas diferentes de dizer o verdadeiro. Na aula de 23 de janeiro de 1980, no Collège de France, o filósofo francês encontra na peça de Sófocles uma aleturgia oracular e religiosa e outra judiciária. No que se refere à primeira, é observável "um dizer verdadeiro que não se pronuncia e que surge de quem o viu pelos próprios olhos" (FOUCAULT, 2010, p. 51). Quanto à segunda, a aleturgia judiciária, manifesta-se pela presença e pela ação efetiva do próprio sujeito. Seguindo a argumentação foucaultiana, é possível encontrar como elemento comum a ambas as modalidades de aleturgia a questão do sujeito, "do eu", nas diferentes formas de veridição. 
De forma derivada a essas questões, o objetivo de Foucault para o curso de 1980 estava na consideração de que é possível estudar "a constituição de uma aleturgia que gira em torno do eu mesmo, do si mesmo, do eu" (FOUCAULT, 2010, p. 53). Para o estudo da manifestação da verdade, apresentará na aula seguinte, proferida em 30 de janeiro, algumas lições extraídas de seus comentários da história de Édipo. Trataremos cada uma dessas separadamente.

A primeira lição refere-se à premissa de que não há exercício de poder sem a manifestação da verdade. A segunda lição é que o círculo da aleturgia somente completa-se por meio de práticas de subjetivação. Por fim, como terceira lição, Foucault sugere que a manifestação da verdade faz mais do que revelar algo que esteja oculto ou desconhecido. Na direção desses argumentos, estudar os procedimentos aletúrgicos implica, diretamente, em uma atitude de recusa a análises ideológicas, as quais suporiam a busca de uma verdade autêntica ou a desocultação de algum pensamento.

A questão que eu gostaria de colocar, ainda uma vez, é essa: como se fez, numa sociedade como a nossa, que o poder não possa se exercer sem que a verdade se manifeste, e se manifeste na forma da subjetividade? $\mathrm{E}$, de outra parte, espera-se nessa manifestação da verdade sob a forma da subjetividade efeitos que estão para além da ordem do conhecimento, mas que são da ordem da salvação e da libertação para cada um e para todos (FOUCAULT, 2010, p. 57).

Para a composição deste campo de problematizações, Foucault propõe-se a desenvolver, ao longo do curso de 1980, outro tipo de atitude investigativa: a anarqueologia. Importa-nos explicitar que a proposição foucaultiana não estava vinculada à construção de um método, ${ }^{1}$ pelo menos no sentido tradicional dessa expressão, mas a constituição de uma "atitude teórico-prática" (2010, p. 62). Parte de uma postura investigativa que se posiciona na contramão de qualquer legitimidade inerente ao exercício do poder. De acordo com esse posicionamento, bastante próximo a algumas tendências do anarquismo (AVELINO, 2010), postula-se que "nenhum poder existe por si" (FOUCAULT, 2010, p. 60). Considerar essa perspectiva como ponto de partida não significa projetar uma sociedade sem relações de poder, nem mesmo considerar que o poder é algo maléfico em si mesmo. Neste momento, é útil recordar uma das inúmeras definições de poder elaboradas por Foucault, em sua fase genealógica, na qual apontava que "o poder não é uma instituição e nem uma estrutura, não é uma certa potência de que alguns sejam dotados: é o nome dado a uma situação complexa numa sociedade determinada" (FOUCAULT, 1999, p. 89).

Estabelecer uma atitude investigativa anarqueológica supõe a produção de "uma atitude analítica que consiste em um gesto de transgressão ao poder, posição analítica que coloca $o$ ato de desobediência como ponto de partida e condição da 
análise" (AVELINO, 2010, p. 24). O gesto de transgressão ao poder, argumentado por Avelino, conduz a uma prática investigativa que recusa as posições universalistas, humanistas ou ideológicas (FOUCAULT, 2010). Recusar tais lugares clássicos na tradição moderna encaminha a possibilidade de tomar somente as práticas para o estudo da constituição dos objetos. Ao revisar suas pesquisas anteriores, Foucault exemplifica essa postura investigativa por meio de seus estudos a respeito da loucura. "É preciso tomar a loucura por um 'x' e se apossar da prática, da prática somente como se não se soubesse nada, e fazer de tal modo sem nada saber sobre $o$ que é a loucura" (FOUCAULT, 2010, p. 63).

Inspirados nessa atitude anarqueológica é que analisaremos, nesse texto, a constituição da docência em suas relações entre poder e verdade. De forma diferenciada em relação aosestudos anteriores (SILVA, 2011), neste texto mobilizaremos outras ferramentas para o estudo da docência. Utilizaremos a governamentalidade enquanto ferramenta conceitual, entretanto, reconhecemos que essa não se esgota nas práticas políticas (CASTRO, 2010), mas, opera na articulação entre o governo de si e o governo dos outros. Nesta direção, pensamos a docência não apenas na formação de agentes políticos no interior de uma racionalidade de Estado, mas também em um jogo sutil de subjetivação no qual os sujeitos, em sua liberdade, assumem-se como profissionais crítico-reflexivos, comprometidos, politicamente, com a transformação da sociedade. Para esse texto selecionamos algumas verdades, consolidadas na primeira metade do último século, que têm constituído-nos como professores e que circulam com muita intensidade na área pedagógica. A produção de um professor reflexivo e o compromisso político da docência são as duas formas de manifestação da verdade que iniciaremos o estudo neste texto.

\section{Docência, governo e verdade: algumas incursões}

Estudos a respeito da constituição contemporânea da docência têm multiplicado-se na contemporaneidade. Tais estudos tratam de mostrar como a docência passa a ocupar um lugar privilegiado nas sociedades atuais. Em uma abordagem mais sociológica, Tardif (2010) estuda esse objeto a partir dos saberes profissionais dos professores, considerando-os como de natureza social. Tal perspectiva é justificada pelo sociólogo canadense por meio de um conjunto de condições. Uma destas é que esse saber é social porque torna-se compartilhado por um conjunto de profissionais que têm uma formação em comum e estão sujeitos a situações e instituições semelhantes. Outra condição é que esse saber é social "porque sua posse e utilização repousam sobre todo um sistema que vem garantir a sua legitimidade e orientar sua definição e utilização" (TARDIF, 2010, p. 12) - ou seja, um conjunto 
de instituições opera na produção da docência, sejam elas universitárias, administrativas ou científicas. Uma terceira condição apontada por Tardif é que o saber é social devido ao fato de seus objetos serem sociais, isto é, a docência é constituída desde práticas sociais.

Como evidencia a história das práticas escolares, aquilo que os professores ensinam e seus modos de ensinar são temporais, alterando-se ao longo do tempo e de acordo com as mudanças sociais. Acerca do trabalho docente, Tardif e Lessard (2009) evidenciam que a docência, por ser uma ocupação tão antiga quanto o Direito ou a Medicina, representa atualmente, uma perspectiva socioeconômica, "um setor nevrálgico sob todos os pontos de vista" (TARDIF; LESSARD, 2009, p. 21). Isso pode ser visto em alguns dados da Organização das Nações Unidas para a Educação, a Ciência e a Cultura (Unesco) apontados pelos autores, de que, atualmente, existem cerca de 60 milhões de professores, trabalhando em todo o mundo.

Longe de ser grupos economicamente marginais, profissões periféricas ou secundárias em relação à economia da produção material, os agentes escolares constituem, portanto, hoje, tanto por causa de seu número como de sua função, uma das principais peças da economia das sociedades modernas avançadas. Nessas sociedades, a educação representa, com os sistemas de saúde, a principal carga orçamentária dos estados nacionais. Portanto, não se pode entender nada das transformações socioeconômicas atuais sem considerar diretamente esses fenômenos (TARDIF; LESSARD, 2009, p. 22).

Ainda que esses impactos não sejam posicionados apenas na dimensão econômica, os autores argumentam que é por essa dimensão que a docência passa a ocupar tal status: "a importância econômica do ensino caminha a par de sua centralidade política e cultural" (TARDIF; LESSARD, 2009, p. 23). Cabe destacar que, desde o século XVII, o ensino escolar tem constituído-se como uma das principais formas de socialização, assim como operou na constituição daquilo que nomeamos como sociedade. Essa constatação não se altera, conforme os autores, nem mesmo diante das condições contemporâneas, pois "esse modo de socialização e formação, que chamamos ensino escolar, não para de expandir-se, ultrapassando em muito a instituição que lhe serve historicamente de suporte, ou seja, a escola" (TARDIF; LESSARD, 2009, p. 23).

De um ponto de vista mais histórico, Nóvoa (1995) examina a constituição da profissão docente. Segundo o historiador, é a partir da segunda metade do século XVIII que podemos pensar em uma história da profissão docente. Questões acerca de um perfil de professor passam a integrar as reflexões daquele período: “deve ser leigo ou religioso? Deve integrar-se num corpo docente ou agir a título individual? De que modo deve ser escolhido e nomeado? Quem deve pagar o seu trabalho? Qual deve ser a autoridade de que deve depender?" (NÓVOA, 1995, p. 15). Essas questões si- 
tuam-se em um quadro de secularização e estatização do ensino, um período no qual a educação desloca-se do controle da Igreja e inicia uma vinculação com o Estado.

Entretanto, esse deslocamento não se apresenta como uma ruptura com o modelo produzido sob a tutela da Igreja, uma vez que, como lembra-nos Nóvoa, "o modelo do professor continua muito próximo do modelo do padre" (1995, p. 15). Dessa perspectiva, os primeiros agrupamentos docentes foram marcadamente caracterizados pela influência das congregações católicas destinadas ao ensino. A partir desta matriz, a docência passa a consolidar-se historicamente com a configuração de duas especificidades "um corpo de saberes e técnicas e um conjunto de normas e de valores específicos da profissão docente" (NÓVOA, 1995, p. 16, grifos do autor).

Simultaneamente com este duplo trabalho de produção de um corpo de saberes e de um sistema normativo, os professores têm uma presença cada vez mais ativa (e intensa) no terreno educacional: o aperfeiçoamento dos instrumentos e das técnicas pedagógicas, a introdução de novos métodos de ensino e o alargamento dos currículos escolares dificultam o exercício do ensino como atividade secundária ou acessória. O trabalho docente diferencia-se como "conjunto de práticas", tornando-se assunto de especialistas, que são chamados a consagrar-lhe mais tempo e energia (NÓVOA, 1995, p. 16).

Ainda que não avancemos na descrição historiográfica proposta por Nóvoa, faz-se relevante, neste momento, destacar os modos pelos quais a docência é produzida por meio de um conjunto de saberes, normas e práticas específicas. Esses saberes e normas são instituídos a partir das condições políticas de um determinado tempo. Assim, pensar a constituição da docência implica em um mapeamento dos modos de regulação dessa atividade. Isso amplia sua significação quando podemos pensar que a docência também é produzida a partir de uma adesão dos sujeitos. Como também lembra-nos Nóvoa, "a profissão docente exerce-se a partir da adesão colectiva (implícita ou explícita) a um conjunto de normas e de valores" (1995, p. 19). São os próprios sujeitos professores que escolhem, em sua liberdade, ocupar esse lugar público de responsabilidade pela formação das novas gerações. Por um lado, tal adesão dirige o profissional a um comprometimento com a grade política do Estado moderno e, por outro lado, apresenta-lhe a um novo modo de experienciar a vida pessoal e profissional: a docência.

\section{Quem quer ser reflexivo? A docência e seus atos de verdade}

Na medida em que a docência institui-se desde um movimento de adesão coletiva, segundo a descrição de Nóvoa (1995), faz-se possível pensar que suas formas de manifestação da verdade não estão circunscritas somente aos regimes públicos. A docência é produzida desde um conjunto de atos de verdade (FOUCAULT, 2010). 
Por atos de verdade Foucault entende "a parte que retorna ao sujeito no processo de aleturgia para que se possa defini-lo" (2010, p. 65). Assim, a docência poderia tornar-se visível pelos diferentes papéis que o sujeito desempenhe: seja como operador, seja como espectador, ou ainda como objeto mesmo da aleturgia. Especificando o argumento trazido, podemos pensar que a docência é produzida no interior de diferentes atos de verdade, nos quais a verdade é manifestada na conduta dos sujeitos. Ou ainda quando o professor, por obediência, submissão ou vontade, toma o centro da cena pedagógica. Alguns desses atos de verdade serão explorados a partir desta seção.

Há pouco mais de duas décadas, um conjunto de novos sentidos acerca da constituição da docência passou a circular na literatura pedagógica internacional. A imagem do professor como um profissional reflexivo exerceu significativo encantamento em inúmeros teóricos desse campo. As abordagens de Schön (1992), Zeichner (1993) e Alarcão (1996), derivadas de algumas teorizações deweyanas, colocaram a profissão docente no interior de um conjunto de novos princípios organizativos. Os professores passam a ser convocados a estabelecer uma reflexão mais sistemática de suas práticas, ora pesquisando individualmente suas práticas profissionais, ora formando comunidades profissionais com seus pares.

A pesquisa de suas práticas e a formação de comunidades, a partir dessas condições, demarcam um conjunto de novas pesquisas no âmbito da profissionalidade docente (NÓVOA, 1995). A consolidação desse modelo imediatamente passou a compor novas pautas políticas dos professores, muitas vezes reivindicadas pelas próprias categorias profissionais. Analisar os dilemas de seu trabalho, assumir novos valores e papéis institucionais e tornar-se protagonista de sua profissionalidade são algumas das premissas que subsidiam essa abordagem teórico-prática. Muitas são as abordagens de tratamento analítico dessa questão, no entanto, atribuiremos maior ênfase à questão das comunidades profissionais, ou seja, à constituição de uma docência que, para além de inserir-se em programas de aprendizagem contínua, consolida-se na reflexão coletiva com seus pares.

No que tange às políticas de formação de professores, têm adquirido grande relevância os programas nomeados como Comunidades de práticas ou Comunidades formativas. A teorização no campo supõe que tais comunidades seriam agrupamentos de professores que trocam experiências, refletem e aprendem coletivamente diante dos dilemas de sua prática profissional. "A comunidade formativa se dá em contextos que permitem a elaboração por parte do professorado de uma cultura própria no seio do grupo e não só a reprodução padronizada da cultura social ou acadêmica dominantes" (IMBERNÓN, 2009, p. 81). Tais arranjos formativos alicerçam-se na possibilidade de cooperação entre os professores. 
Essa dimensão colaborativa da constituição da profissão é nomeada por Fullan e Hargreaves (2000) como "profissionalismo interativo". Segundo os autores, "O profissionalismo interativo envolve a redefinição do papel dos professores e de suas condições de trabalho" (2000, p. 82). De acordo com esse campo pedagógico, as trocas permanentes de experiências e as reflexões produzidas entre os professores produziriam uma nova cultura profissional - docências interativas mobilizadas a partir de culturas profissionais colaborativas.

Essa abordagem, também, pretende constituir-se como uma modalidade de inovação nas práticas profissionais dos professores e, ao mesmo tempo, uma formação voltada para a colaboração como princípio fundamental. O profissionalismo interativo propõe-se a tornar-se o elemento central dessa questão, produzindo, segundo os autores Fullan e Hargreaves, um conjunto de vantagens:

- um juízo prudente como o cerne do profissionalismo;

- culturas cooperativas de trabalho;

- normas de desenvolvimento contínuo em que novas idéias são buscadas dentro e fora do local de trabalho;

- reflexão na prática e sobre ela, na qual recebe lugar de destaque o desenvolvimento individual e pessoal, além do desenvolvimento e da avaliação coletivos;

- maior domínio do campo de ação, maior eficácia e satisfação na profissão de professor (2000, p. 82).

O conhecido documento da Unesco relacionado à educação para o século XXI, organizado por Jacques Delors (2003), dentre outros aspectos, discute as relações existentes entre crescimento econômico e desenvolvimento humano. $\mathrm{O}$ texto parte do grande crescimento econômico ocorrido a partir de 1950, que teve como eixos principais o aumento da produtividade e o progresso tecnológico. Entretanto, conforme essa perspectiva, tal crescimento aconteceu tão rápida quanto desigualmente. Dessa forma, o desafio educacional para o novo século estaria na conjugação da economia com o desenvolvimento humano, ou seja, em ampliar os fins econômicos da educação.

Enuncia-se no relatório uma articulação entre capital humano e escolarização básica. A inventividade passa a operar como um desafio, permanente, para a produção de uma docência criativa. Delors (2003), em seu relatório, ainda é mais enfático ao afirmar que os processos de escolarização devem "acompanhar e, até, antecipar-se às transformações tecnológicas que afetam permanentemente a natureza e a organização do trabalho" (p. 71). A questão pontuada estaria em estabelecer uma concepção de educação articulada à noção de desenvolvimento humano, fazendo com que cada estudante "tome o seu destino nas mãos e contribua para o progresso da sociedade em que vive" (p. 82). No que tange ao lugar dos professores na escola do século XXI, afirma-se que o desafio posto à docência está na sua reinvenção. 
O trabalho do professor não consiste simplesmente em transmitir informações ou conhecimentos, mas em apresentá-los sob a forma de problemas a resolver, situando-os num contexto e colocando-os em perspectiva de modo que o aluno possa estabelecer a ligação entre a sua solução e outras interrogações mais abrangentes (DELORS, 2003, p. 153).

O desafio está, então, em desencadear novas formas de aprender, as quais sejam criativas e que, com isso, estimulem a criatividade dos estudantes. Formas essas de aprender que privilegiem a resolução de problemas e que mobilizem a constituição de uma docência com características peculiares. O relatório de Delors (2003), ao descrever o ato de ensinar, enuncia que a grande força dos professores na atualidade "reside no exemplo que dão, manifestando sua curiosidade e sua abertura de espírito, e mostrando-se prontos a sujeitar as suas hipóteses à prova dos fatos e até a reconhecer os próprios erros. Devem, sobretudo, transmitir o gosto pelo estudo" (p. 157). Sob essa gramática, podemos identificar os modos pelos quais as condutas dos professores são tomadas como ferramentas apropriadas ao desenvolvimento da sociedade atual, ao mesmo tempo em que atitudes dos professores são posicionadas como modos de vida delineados pela curiosidade e pelo espírito de abertura.

\section{Comprometer-se com o seu tempo: inclusão e políticas da docência}

As reformas contemporâneas nas políticas e práticas de escolarização têm apostado na produção de uma nova democracia (POPKEWITZ, 2008). Projetar a inclusão de diferentes sujeitos nos sistemas de ensino, promover práticas de resolução de problemas e estimular programas de formação ao longo da vida são algumas das tendências destes tempos. Segundo Popkewitz (2008), a construção e a efetivação desta nova democracia passam pelos temas da salvação pela ciência e pela produção de uma comunidade colaboradora. Nesse cenário, a pedagogia redefine-se pelo objetivo político da redenção, no qual a escolarização busca a formação de "uma individualidade ordenada pelas disposições, pelas sensibilidades e pela consciência, que fazem do ator civilizado uma pessoa capaz de evoluir numa cultura e numa economia globais" (POPKEWITZ, 2008, p. 243).

No interior desse cenário, pensar nas comunidades locais como espaço de intervenção tem-se apresentado como uma forte tendência. Diferentes programas nas áreas de educação, saúde, meio ambiente e criminalidade, dentre outras, posicionam as comunidades como campos de intervenção privilegiados, sobretudo ao terem como horizonte uma sociedade democrática. Conforme sugerem alguns estudos (POPKEWITZ, 2009; POPKEWITZ; OLSSON; PETERSON, 2009; O’MALLEY, 2007), diferentes "qualidades performativas comunitárias" são evocadas na busca 
pela comunidade como espaço de educação preventiva, de formação cidadã e de intervenções políticas democráticas. "A comunidade representa um tema redentor no envolvimento e no empoderamento, no qual a resolução de problemas produz uma cidadania responsável" (POPKEWITZ; OLSSON; PETERSON, 2009, p. 86).

O'Malley (2007) argumenta que, sob a gramática do neoliberalismo, as comunidades destacam-se como foco de políticas de seguridade. Nesse sentido, tais espaços são apontados como mais comprometidos com seus membros por melhor entenderem os seus problemas, por serem mais flexíveis e criativos que as instituições burocráticas, focalizam-se nas demandas e potencialidades locais, e suas atividades são mais "baratas" que os demais serviços públicos. Dessa forma, faz-se possível perceber algumas articulações entre as comunidades e as novas políticas de seguridade.

No Brasil da segunda metade do século XX, um conjunto de tendências teóricas procurou apresentar e problematizar as aproximações entre a instituição escolar e o mundo social mais amplo. Democracia, cidadania, autonomia, emancipação e participação foram alguns dos sentidos teleológicos para a educação produzidos desses lugares teóricos. A premissa de que a educação somente faz sentido quando dialoga com os contextos sociais e/ou nestes interfere, marca uma importante tradição pedagógica brasileira, autointitulada como progressista. Para situar como essa concepção produziu implicações para a constituição da docência, recorreremos, ainda que rapidamente, às concepções pedagógicas de Álvaro Vieira Pinto e Paschoal Lemme.

Lemme, em suas memórias, publicadas no ano de 1988, discute uma possibilidade educativa diferenciada dos processos conhecidos como instrução ou ilustração. $\mathrm{O}$ autor entende que há uma forma de educação que passa pelos regimes formais de escolarização, mas vai além desses: a educação política. Um processo formativo com essa conotação permite que o indivíduo "passe a compreender a própria estrutura da sociedade em que vive, o sentido das transformações que estão se processando nela, e assim, de mero protagonista inconsciente do processo social, passe a ser um membro atuante na sociedade" (LEMME, 1988, p. 73). A ação pedagógica, dessa perspectiva, conduziria os diferentes sujeitos a intervenções nos contextos em que vivem.

O educar politicamente, proposto pelo pensador, toma como objeto prioritário "revelar ao indivíduo a verdade sobre o contexto social em que vive e sua posição nele, para que essa verdade exerça todo o poder mobilizador que somente a verdade possui" (LEMME, 1988, p. 74). Em nome dessa verdade, o alvo do processo de ensino dessa abordagem pedagógica é o povo, pois este precisaria exercer um controle mais efetivo do ensino a que seus filhos estão submetidos. Tanto para essa parcela da população, quanto para os educadores e administradores públicos, o desafio 
posto está em posicionar o sentido dos processos pedagógicos para além da sala de aula, comprometendo-os com posturas políticas transformadoras.

Em uma direção aproximada, Vieira Pinto (1982) em seu texto Sete lições sobre educação de adultos, ao demarcar as condições antropológicas e históricas da educação, pretende apresentar um compromisso orgânico entre as práticas escolarizadas e as práticas sociais. $\mathrm{O}$ autor retoma algumas clássicas dimensões das práticas educativas (processo, fato existencial, fato social, fenômeno cultural e atividade teleológica, dentre outras). Entretanto, enuncia uma dimensão absolutamente diferenciada em relação à tradição pedagógica que o antecedeu. Vieira Pinto situa a educação como uma modalidade de "trabalho social".

A educação é parte do trabalho social porque:

- trata de formar os membros da comunidade para o desempenho de uma função no âmbito da atividade total;

- o educador é um trabalhador (reconhecido como tal);

- no caso especial da educação de adultos, dirige-se a outro trabalhador, a quem tenciona transmitir conhecimentos que lhe permitam elevar-se em sua condição de trabalhador (1982, p. 39).

A articulação enunciada e visibilizada por Vieira Pinto entre educação, comunidade e trabalho social permite-nos reconhecer a educação como um campo de regulação da vida dos sujeitos em comunidade. A ideia de trabalho social implica uma ação sobre os outros, uma ação em relação a agrupamentos humanos dispostos a aprender e, ao mesmo, implica em uma disposição dos educadores em assumir sua profissão como um modo de vida. Afora essa questão, importa pensar que o educar politicamente de Lemme, articulado à educação como trabalho social de Vieira Pinto, permite-nos refletir as aproximações entre educação e participação comunitária na contemporaneidade.

Diante de seu compromisso político, a pedagogia progressista dirige a atuação dos educadores para a intervenção nas comunidades em que estão inseridos. A expressão designada para essa ênfase é participação comunitária. São derivados dessa concepção conceitos e práticas como cidades educadoras, conselhos escolares, autonomia das escolas, planejamento participativo, educação inclusiva e avaliação emancipatória, dentre outros. Trabalha-se com a premissa de que é dever de um educador progressista entender que "é a própria comunidade local que, tendo a escola como algo seu, se faz igualmente presente na condução da política educacional da escola" (FREIRE, 1995, p. 74-75).

Parece-nos que é no interior dessa matriz pedagógica, desenvolvida no Brasil entre as décadas de 1950 e 1970, que se torna possível situar as comunidades locais como espaços de intervenção pedagógica. Entendemos que tal configuração pedagógica, ao tomar as comunidades como espaços de intervenção pedagógica, 
propõe-se a regular a subjetividade docente. Entretanto, tal regulação não ocorre de modo vertical, mas conta com a liberdade e vontade dos professores. Nessa lógica, assumir-se como professor implica em aceitar o desafio de educar politicamente, em planejar sua prática profissional como um trabalho social e estabelecer as comunidades como campos de intervenção pedagógica. Fazer-se professor envolve em desejar e aceitar um modo de vida comunitário, politicamente responsável.

\section{Considerações finais}

Ao longo dessa análise pretendemos examinar algumas verdades que perfazem a constituição contemporânea da docência. Ao reconhecermos a docência como um campo de práticas, entendemos que sua produção desenvolve-se em interface com estratégias políticas de governo. Entretanto, tal modo de compreensão do governo não sugere que tais práticas sejam ações verticalizadas em relação aos sujeitos, mas envolvem a adesão dos próprios sujeitos constituídos. Assim, em aproximação aos estudos Foucaultianos, encaminhamos que a docência é tensionada por estratégias de governo de si e dos outros.

É possível ultrapassar a linha dos gerenciamentos contemporâneos da ação docente? Podemos extrapolar as fronteiras dos diferentes e sedutores fios dessa trama? Faz-se pertinente, diante das contingências do presente, a instauração de espaços de enfrentamento a tudo isso? Ainda que não seja nossa intenção aprofundar aqui esse conceito, seguindo o próprio Foucault, poderíamos pensar na instauração de movimentos de contraconduta (FOUCAULT, 2008). Tal conceito foucaultiano dirige-se no "sentido de luta contra os procedimentos postos em prática para conduzir os outros" (p. 266). Outra possibilidade, enunciada pelo filósofo no curso de 1980, Do governo dos vivos, estaria na instauração de outra atitude frente às relações entre o poder e o saber, uma atitude que parte do pressuposto de que nenhum poder existe por si mesmo.

$\mathrm{Na}$ esteira do pensamento de Foucault, sugerimos que se comprometer, radicalmente, com o diagnóstico do presente implica um pertencimento e uma tarefa. Tal comprometimento encaminha-me a pensar que "nenhum poder, qualquer que seja, é evidente ou inevitável! Qualquer poder, consequentemente, não merece ser aceito no jogo! Não existe legitimidade intrínseca do poder" (FOUCAULT, 2010, p. 60). Dessa forma, ao diagnosticar diferentes jogos de verdade operantes na produção da docência contemporânea, também objetivamos construir ferramentas de intervenção política. A principal ferramenta que mobilizamos, ao produzir essa analítica, foi o trabalho teórico. 
A noção de trabalho teórico, aqui mobilizada, não pressupõe a construção de teorias estáveis e universais, e não consiste em estabelecer teses incontestáveis que denotariam a construção de um sistema. Na companhia de Foucault, privilegiamos um modo de olhar que descreva os traços, os deslocamentos ou tensionamentos visíveis na sociedade contemporânea. Nessa direção, o filósofo francês posiciona-se na condição de um teórico negativo.

\begin{abstract}
Essa necessidade, portanto, não aparece jamais como plano de um edifício permanente; não é preciso lhe reclamar e impor as mesmas exigências como se tratasse de um plano: trata-se, ainda uma vez, de traçar um deslocamento, quer dizer traçar não edifícios teóricos, mas deslocamentos pelos quais as posições teóricas não cessam de se transformar. Após tudo, existem teologias negativas: digamos que eu sou um teórico negativo. Então, uma nova curva, um novo traço, e uma vez mais um retorno sobre ela mesma, sobre o mesmo tema (FOUCAULT, 2010, p. 59).
\end{abstract}

Pretendemos mostrar dois jogos de verdades que nos têm envolvido na constituição da docência contemporânea, os quais dizem respeito a reflexividade pedagógica e o compromisso político do professor. Tal entendimento alicerça-se na perspectiva de que as verdades não são produzidas a priori das práticas escolares, nem mesmo constituem-se em um núcleo essencial do discurso pedagógico. Essas verdades conduzem a fabricação de sistemas de raciocínio pedagógico, da forma como sugere-nos Popkewitz (2009), na medida em que interagem com as pautas sociais de seu tempo. Entretanto, uma retomada faz-se fundamental, visto que tais sistemas contam permanentemente com a adesão dos professores, uma vez que, segundo Foucault apresentou-nos no curso de 1980, as verdades constituem-nos na medida em que nos inclinamos ao seu poder, assumindo-a como forma de viver no verdadeiro. Entretanto, a produção das subjetividades docentes não se esgota nessa adesão: anarqueologicamente postulamos que nenhum poder é inevitável.

\title{
Teaching, government and truth: elements for an anarchaeological analysis
}

\section{Abstract}

This article examines two sets of truths that are mobilized in the constitution of contemporary teaching, namely: reflexivity pedagogical and political commitment of the teacher. This understanding is founded on the view that truths are not produced in advance of school practices, are not even on a core of pedagogical discourse. Such truths lead to manufacturing systems for pedagogical reasoning in that interact with the social guidelines of the time. However, these systems rely permanently with the accession of teachers, since, according to the indications that the philosopher Michel Foucault presented in the course of 1980, the truths we are in that we bow to his power, taking it as a way to live in the true.

Keywords: Teaching. Government. Michel Foucault. Philosophy of education. 


\section{Nota}

1 Em texto recente, Veiga-Neto e Lopes (2010) apontam que é possível encontrarmos teoria e método nos Estudos Foucaultianos se tomarmos essas expressões em um sentido amplo, ou seja, se as entendemos "mais [como] ferramentas do que máquinas acabadas" (p. 42).

\section{Referências}

ALARCÃO, Isabel. Reflexão crítica sobre o pensamento de D. Schön e os programas de formação de professores. In: ALARCÃO, Isabel (Org.). Formação reflexiva de professores: estratégias de supervisão. Porto: Porto Editora, 1996. p. 9-39.

AVELINO, Nildo. Apresentação: Foucault e a anarqueologia dos saberes. In: FOUCAULT, Michel. Do governo dos vivos: curso no Collège de France, 1979-1980: excertos. Trad., transcrição e notas de Nildo Avelino. Rio de Janeiro: Achiamé, 2010. p. 7-27.

CASTRO, Edgardo. Lecturas foucaulteanas: una historia conceptual de la biopolítica. Edição. Local de publicação: Unipe Editorial, 2010.

DELORS, Jacques (Org.). Educação: um tesouro a descobrir. 8. ed. São Paulo: Cortez; Brasília: MEC/Unesco, 2003.

FOUCAULT, Michel. Do governo dos vivos: curso no Collège de France, 1979-1980: excertos. Tradução, transcrição e notas de Nildo Avelino. Rio de Janeiro: Achiamé, 2010.

. Segurança, território, população. São Paulo: Martins Fontes, 2008.

. História da sexualidade I: a vontade de saber. 13. ed. Rio de Janeiro: Graal, 1999.

FREIRE, Paulo. Política e educação. 2. ed. São Paulo: Cortez, 1995.

FULLAN, Michael; HARGREAVES, Andy. A escola como organização aprendente: buscando uma educação de qualidade. 2. ed. Porto Alegre: Artmed, 2000.

IMBERNÓN, Francisco. Formação permanente do professorado: novas tendências. São Paulo: Cortez, 2009.

LEMME, Paschoal. Memórias. v. 3. São Paulo: Cortez, 1988.

NÓVOA, António (Org.). Profissão professor. 2. ed. Porto: Porto Editora, 1995.

O'MALLEY, Pat. Experimentos en gobierno: analíticas gubernamentales y conocimiento estratégico del riesgo. Revista Argentina de Sociología, [On line], v. 5, n. 8, p. 153-173, 2007. Disponível em: <http://www.scielo.org.ar/scielo.php?script=sci_arttext\&pid=S1669-32482007000100008\&ln $\mathrm{g}=\mathrm{es} \& \mathrm{nrm}=\mathrm{iso}>$. Acesso em: 5 abr. 2014.

PINTO, Álvaro Vieira. Sete lições sobre educação de adultos. São Paulo: Cortez, 1982.

POPKEWITZ, Thomas. Uma perspectiva comparativa das parceiras, do contrato social e dos sistemas racionais emergentes. In: TARDIF, Maurice; LESSARD, Claude (Orgs.). $O$ ofício de professor: história, perspectivas e desafios internacionais. Petrópolis: Vozes, 2008. p. 234-254. . El cosmopolitismo y la era de la reforma escolar. Madrid: Ediciones Morata, 2009. 
POPKEWITZ, Thomas; OLSSON, Ulf; PETERSSON, Kenneth. Sociedade de aprendizagem, cosmopolitismo, saúde pública e prevenção à criminalidade. Educação e Realidade, local de publicação, v. 2, n. 34, p. 73-96, maio/ago. 2009.

SCHÖN, Donald. Formar professores como profissionais reflexivos. In: NÓVOA, António (Org.). Os professores e a sua formação. Lisboa: D. Quixote e IIE, 1992.

SILVA, Roberto Rafael Dias da. A constituição da docência na ensino médio no Brasil contemporâneo: uma analítica de governo. 2011. Tese (Doutorado em Educação) - Universidade do Vale do Rio dos Sinos, São Leopoldo, 2011.

TARDIF, Maurice; LESSARD, Claude. O trabalho docente: elementos para uma teoria da docência como profissão de interações humanas. 5. ed. Petrópolis: Vozes, 2009.

TARDIF, Maurice. Saberes docentes e formação profissional. 10. ed. Petrópolis: Vozes, 2010.

VEIGA-NETO, Alfredo; LOPES, Maura Corcini. Há teoria e método em Michel Foucault? - implicações educacionais. In: CLARETO, Sônia; FERRARI, Anderson (Orgs.). Foucault, Deleuze e Educação. Juiz de Fora: Ed. UFJF, 2010. p. 33-47.

ZEICHNER, Kennett. A formação reflexiva de professores: ideias e práticas. Lisboa: Educa, 1993. 